\title{
Effect of a Bacterial Grass Culture on the Plant Growth and Disease Control in Tomato
}

*Corresponding author Tel: $+82-62-530-2126$

Fax: $+82-62-530-2139$

E-mail:kimkil@chonnam.ac.kr

Received June 3, 2017

Revised August 23, 2017

Accepted August 25, 2017

\author{
Yong Seong Lee ${ }^{1}$, Kyaw Wai Naing ${ }^{2}$, and Kil Yong Kim ${ }^{1 *}$ \\ 'Division of Food Technology, Biotechnology and Agrochemistry, Institute of Environmentally-Friendly \\ Agriculture, Chonnam National University, Gwangju 61186, Korea \\ ${ }^{2}$ Vegetable and Fruit Research and Development Center, Hlegu 11374, Myanmar
}

\begin{abstract}
This study aimed to investigate the plant growth-promoting and biocontrol potential of a grass culture with Paenibacillus ehimensis KWN8 on tomato. For this experiment, treatments of a chemical fertilizer (F), a bacterial grass culture (G), a $1 / 3$ volume of $G$ plus $2 / 3 F(G F)$, and $F$ plus a synthetic fungicide (FSf) were applied to tomato leaves and roots. The result showed that the severity of Alternaria solani and Botrytis cinerea symptoms were significantly reduced after the application of the bacterial grass culture (G and GF) and FSf. In addition, root mortality in G and GF was lower compared to F. Tomato plants treated with G or GF had better vegetative growth and yield compared to F. Application of $\mathrm{G}$ affected the fungal and bacterial populations in the soil. In conclusion, treatment with a bacterial grass culture decreased disease severity and increased tomato growth parameters. However, there were no statistically significant correlations between disease occurrence and tomato yields. This experiment presents the possibility to manage diseases of tomato in an environmentally friendly manner and to also increase the yield of tomato by using a grass culture broth containing $P$. ehimensis KWN38.
\end{abstract}

Keywords: Alternaria solani, Bacterial grass culture, Biocontrol, Botrytis cinerea, Paenibacillus ehimensis KWN38

\section{Introduction}

Tomato (Solanum lycopersicum) is one of the most important vegetables and is consumed fresh or as processed foods, such as pastes, sauces, juices, or dehydrated desserts (Bergougnoux, 2014). It is a rich source of vitamin C, carotenoids, folic acid, ascorbic acid, flavonoids, a-tocopherol, and potassium that are required for humans (Riso et al., 2004; Willcox et al., 2003). Tomato is often infected with several plant pathogens, such as bacteria, viruses, and fungi, causing plant diseases that pose serious yield restraints (Foolad et al., 2008). In South Korea, the planted area of tomato is steadily

Research in Plant Disease

pISSN 1598-2262, elSSN 2233-9191

www.online-rpd.org increasing (5,270 ha in 2010). Due to this increase in the cultivation area of tomato, the occurrence of various diseases is also increasing. In particular, fungal diseases of tomato are severe (Kang et al., 2011). The early blight disease of tomato, caused by Alternaria solani (Ellis and Martin) Jones and Grout is one of the foliar diseases of tomato in greenhouses and open fields (Jones et al., 1991). This pathogen has the ability to rapidly spread on the aerial parts of tomato plants, causing serious leaf blight and even complete defoliation (de la Noval et al., 2007). Gray mold disease of tomato, caused by Botrytis cinerea, usually occurs on stems of tomato plants and girdles the stem by producing phytotoxic compounds and cell wall-degrading enzymes (Williamson et al., 2007). In conventional farming systems, excessive use of synthetic fungicides to control fungal diseases hampers food safety and the environment. Since the biocontrol of plant fungal 
diseases by antagonistic strains substantially reduces the use of chemical pesticides, it is a preferable alternative for safer crop production systems (Trabelsi and Mhamdi, 2013). Thus, several studies have focused on the biological control of plant pathogens using antagonistic microorganisms. Some bacteria genera such as, Paenibacillus, Bacillus, and Pseudomonas, not only control plant fungal diseases but also promote plant growth (Ahemad and Khan, 2012; Chaudhry et al., 2013; Myresiotis et al., 2014).

The genus Paenibacillus, first defined by Ash et al. (1993), occurs in a variety of environments, such as soil, water, the rhizosphere, and plant roots (Lal and Tabacchioni, 2009). Some species of this genus have gained attention in agriculture because of their ability to control plant diseases and promote plant growth (Nielsen and Sorensen, 1997). Many Paenibacillus species produce antimicrobial substances considered as natural pesticides, which can affect a broad spectrum of microorganisms (von der Weid et al., 2003), and are antagonists against plant root pathogens (Bloemberg and Lugtenberg, 2001). In addition, several species of Paenibacillus produce extracellular organic secondary metabolites and cell wall-degrading enzymes, such as chitinase and cellulase, and proteases, in the culture broth. These enzymes have direct inhibitory effects on the growth of several plant fungal pathogens, including $A$. solani and B. cinerea (Filho et al., 2010; Huang et al., 2013; Naing et al., 2014a; Shaheen et al., 2011; Zhao et al., 2011). The control of soil-borne plant fungal and bacterial pathogens by Paenibacillus ehimensis has been previously reported (Algam et al., 2013; Son et al., 2009; Naing et al., 2014a, 2014b). P. ehimensis KWN38 was isolated from the rhizosphere of pepper at the seashore of Jellanamdo, Korea, and showed strong antifungal activities against several plant pathogens (Naing et al., 2014a). In our previous studies, we have developed a grass culture medium that can support mass production of $P$. ehimensis KWN38 on a commercial scale (Naing et al., 2014b). However, successful control of both underground and aerial diseases of tomato by $P$. ehimensis in greenhouse or field conditions has not yet been investigated using the developed grass culture medium with P. ehimensis KWN38. Therefore, the aims of this study were to determine the effects of $P$. ehimensis KWN38 culture broth on fungal disease incidence, plant growth, and tomato yield in greenhouses, as well as to elucidate the dynamics of bacterial and fungal populations in the root zone and soil enzyme levels.

\section{Materials and Methods}

Greenhouse experiment. The experiments to investigate the effect of a bacterial grass culture on tomato growth and fungal disease control were carried out in the greenhouses of Chonnam National University in Gwangju, Korea. Soil type at this site is a loam (http://soil.rda.go.kr/geoweb). The tomato cultivar used was Younghwa (Daenong Company). Tomato seeds were sown in bed soil (Bio bed soil I, Heong Nong Seed, Korea) in $54 \times 45 \mathrm{~mm}^{2}$ plastic cell plug trays, and then grown at $24^{\circ} \mathrm{C}$ and $60 \%$ relative humidity in an artificially illuminated room (12,000 lux) with a 16-h photoperiod. Twelve four-week-old seedlings were transplanted in a plot with a raised bed with a row spacing of $0.6 \mathrm{~m}$ and a plant spacing of $0.4 \mathrm{~m}$ within rows on August 21 of 2013. The experimental area of one plot was a $2.5 \times 1.0 \mathrm{~m}^{2}$. The experiment was arranged in a randomized complete block design (RCBD) with four treatments and three replications. Treatments were bacterial grass culture $(G)$, chemical fertilizer (F), 1/3 volume of $G$ plus 2/3 F (GF), and $F$ plus synthetic fungicide (active ingredients include $45 \%$ carbendazim and 9\% Metalaxyl-M, Lidochamgold, Seongbo Chemical) (FSf). To prepare $\mathrm{G}$ for use in this experiment, a grass culture medium (g/l; fresh Kentucky blue grass powder 178; urea 2.8; single superphosphate 8.8; potassium chloride 1.6; magnesium sulfate 1.0; calcium chloride 1.0; yeast 0.1 ; sodium molybdate 0.05; zinc sulfate 0.06; crab shell powder (Purne Co., Korea) 0.8; gelatin powder (Geltech Co., Korea) 0.2) was autoclaved, inoculated with $P$. ehimensis KWN38 and incubated for 5 days at $30^{\circ} \mathrm{C}$ (Naing et al., 2014b). The $F$ treatment (10.2: 5.15: $6.1 \mathrm{~kg} ; \mathrm{N}: \mathrm{P}_{2} \mathrm{O}_{5}: \mathrm{K}_{2} \mathrm{O}$ per $1,000 \mathrm{~m}^{2}$ ) was applied directly to soil using urea for $\mathrm{N}$, mono superphosphate for $\mathrm{P}_{2} \mathrm{O}_{5}$, and potassium chloride for $\mathrm{K}_{2} \mathrm{O}$ by the chemical fertilizer recommendation for greenhouse tomatoes in Korea on July 21, September 21, and October 21 of 2013. A half amount of the total chemical fertilizer for each F, FSf, and GF treatment was applied to the soil by side-dressing as a basal application before transplanting the seedlings, while the remaining half was divided into two more side dressings applied one and two months after transplanting the seedlings. Chemical fertilizer was dissolved with distilled water and used. The GF treatment received $1 / 3$ volume of $G$ with $2 / 3$ amount of $F$. Ninety-seven $\mathrm{ml}$ and $32 \mathrm{ml}$ of $\mathrm{G}$ were treated weekly to the root zone of each tomato plant in the G and GF, respectively, treatments for 16 weeks. After the FSf treatment was pre- 
pared by dissolving $1.0 \mathrm{~g}$ fungicide into $1 \mathrm{I}$ of distilled water, it was applied at the same time in each plot. Three additional sprays in all treatments were applied to the foliar portion of the plants every 20 days between 60 days after transplanting (DAT) and 90 DAT after the first symptoms of early blight and gray mold disease occurred on the leaves and stems. For foliar application, a half amount of the total chemical fertilizer for F was applied after dissolving with distilled water. Ninetyseven $\mathrm{ml}$ and $32 \mathrm{ml}$ of $\mathrm{G}$ were applied to the leaf surface of one tomato plant in the $G$ and $G F$, respectively. The soil moisture conditions were maintained at moisture contents not lower than $50 \%$. In order to maintain the soil moisture, irrigation was applied to the furrow. Soil moisture was measured by an HMM-200 Pro (Hanyoung Systems, Korea). Side shoots were removed weekly to maintain a single stem, which was trellised using a wire.

Measurement of growth and disease incidences in tomato plants. Three random plants from 12 plants in each treatment were sampled to measure the vegetative growth and yield parameters at 30,60, and 90 DAT. The results were expressed as an average per plant. The plants were cut at their base for measuring height and fresh weight. Plant height was measured by a measuring tape. Shoot fresh weight was measured with a digital electric weight balance (SW-1S, CAS Inc., Korea). The soil around the base of the stem was dug deeply by a spade and both the root and soil samples were collected. The roots were washed under running tap water and fresh weights were measured immediately after blotting dry. Dry weights were measured using the digital electric weight balance after the samples were kept in a drying oven at $70^{\circ} \mathrm{C}$ for $72 \mathrm{~h}$. To obtain yield parameters, the fruits were harvested, and the total number and weight per plant were recorded at 30,60, and 90 DAT. Natural occurrences of Alternaria solani and Botrytis cinerea were investigated. The level of fungal disease incidence was calculated as the ratio of diseased leaf number per total leaf number. When a clear blight disease symptom was observed on a leaf surface, the leaf was considered as diseased. The level of gray mold disease was calculated from the ratio of diseased stem length per total stem length. At final sampling (90 DAT), root samples from four different locations per plant were washed and assayed for root mortality caused by Phytophthora root rot, according to the modified method of Knievel (1973). Dried fresh roots $(500 \mathrm{mg}$ ) were added to a $25-\mathrm{ml}$ conical tube (SPL Life Sciences, Korea) containing $10 \mathrm{ml}$ of $0.6 \%$ 2,3,5-triphenyltetrazolium chloride in $0.05 \mathrm{M}$ phosphate buffer ( $\mathrm{pH} 7.4)$, and incubated for $24 \mathrm{~h}$ in the dark at $30^{\circ} \mathrm{C}$. After incubation, roots were rinsed twice with deionized water. Formazan present in the root was extracted twice with 95\% ethanol at $70^{\circ} \mathrm{C}$ for $4 \mathrm{~h}$. Combined extracts were adjusted to a final volume of $20 \mathrm{ml}$ with $95 \%$ ethanol. Absorbance was read at $490 \mathrm{~nm}$ with a UV-spectrophotometer (UV-1650PC, Shimadzu, Japan). A standard curve was constructed using different proportions of living roots and killed roots to calculate root mortality.

Total bacterial and fungal populations in soil. When the plants were sampled for measurement of growth parameters at 90 DAT, $500 \mathrm{~g}$ soil samples from around the roots of plants were collected. After the soil samples were air-dried in a dark room, they were sieved through a 2-mm sieve. One gram of soil sample was serially diluted to $10^{-4}$ and $10^{-5}$ times by sterilized distilled water and each soil sample suspension $(100 \mu \mathrm{l})$ was spread on tryptone soy agar (TSA) and potato dextrose agar (PDA) plates for counting the culturable bacterial and fungal populations. To prevent bacterial growth, 0.2 $\mathrm{g} / \mathrm{l}$ streptomycin sulfate was added into PDA medium just before pouring into Petri dishes. Each assay was performed with three replications.

Enzyme activity in soil. For assays of enzyme activity, the same soil samples as described above were used. Dehydrogenase activity (DHA) was determined following the method of Tabatabai (1982) with little modification. Three grams of soil, $0.3 \mathrm{~g} \mathrm{CaCO}_{3}, 500 \mu \mathrm{l}$ of 3\% 2,3,5-triphenyltetrazoliumchloride (TTC) solution, and $1.25 \mathrm{ml}$ pure water were added to a conical tube and the cap was tightly closed. The samples were incubated for $24 \mathrm{~h}$ at $37^{\circ} \mathrm{C}$. Ten milliliters of methanol was added to the mixture and shaken for $1 \mathrm{~min}$, and the upper methanol layer was filtered through Whatman No. 2 filter paper. This filtering was repeated four times until the reddish color disappeared from the soil. DHA, in terms of 1,3,5-triphenylformazan (TPF) formation, was determined spectrophotometrically at $485 \mathrm{~nm}$. A standard curve was made from $0-20 \mu \mathrm{g} / \mathrm{ml}$ of TPF. The results were expressed as $\mathrm{g}$ TPF/g dry sample. Cellulase activity assay in the soil was performed using the method of Deng and Tabatabai (1994). Briefly, a soil sample (1 g) was incubated with $6.5 \mathrm{ml}$ of sodium acetate buffer ( $50 \mathrm{mM}, \mathrm{pH} 5.5), 3 \mathrm{ml}$ of $1 \%$ carboxy- 
methyl cellulose (CMC), and $0.2 \mathrm{ml}$ toluene at $30^{\circ} \mathrm{C}$ for $24 \mathrm{~h}$. The mixture was filtered through Whatman No.2 filter paper. The filtrate $(500 \mu \mathrm{l})$ and $1.5 \mathrm{ml}$ of 3,5-dinitrosalicylic acid (DNS) solution mixture were heated in boiling water for $5 \mathrm{~min}$. The amount of reducing sugars in the mixture was measured at
$550 \mathrm{~nm}$ using a spectrophotometer (UV-1650 PC, Shimadzu). Each assay was carried out using three replications.

Statistical analysis. Experimental data were analyzed using standard analysis of variance (ANOVA) followed by least

Table 1. Vegetative growth and yield parameters of tomato plants as affected by different treatments

\begin{tabular}{|c|c|c|c|c|c|c|c|c|c|c|c|c|c|c|c|}
\hline \multirow[t]{2}{*}{ DAT } & \multirow{2}{*}{$\begin{array}{c}\text { Treatment } \\
\mathrm{F}\end{array}$} & \multicolumn{2}{|c|}{$\begin{array}{l}\text { Plant height } \\
\text { (cm) }\end{array}$} & \multicolumn{2}{|c|}{$\begin{array}{l}\text { Plant fresh } \\
\text { weight } \\
\text { (g/plant) }\end{array}$} & \multicolumn{2}{|c|}{$\begin{array}{l}\text { Plant dry } \\
\text { weight } \\
\text { (g/plant) }\end{array}$} & \multicolumn{2}{|c|}{$\begin{array}{l}\text { Root fresh } \\
\text { weight } \\
\text { (g/plant) }\end{array}$} & \multicolumn{2}{|c|}{$\begin{array}{c}\text { Root dry } \\
\text { weight } \\
\text { (g/plant) }\end{array}$} & \multicolumn{2}{|c|}{$\begin{array}{c}\text { Fruit number } \\
\text { per plant }\end{array}$} & \multicolumn{2}{|c|}{$\begin{array}{c}\text { Fruit weight } \\
\text { (g/plant) }\end{array}$} \\
\hline & & 193.3 & A & 364.0 & $A$ & 48.6 & $A$ & 18.5 & $A$ & 3.8 & $A$ & 24.8 & A & 228 & $A$ \\
\hline \multirow{4}{*}{30} & FSf & 207.7 & A & 461.0 & $A$ & 58.3 & A & 20.5 & $A$ & 4.0 & A & 22.0 & A & 246 & A \\
\hline & G & 198.5 & A & 492.0 & A & 65.6 & A & 20.6 & $A$ & 4.3 & A & 24.6 & A & 257 & A \\
\hline & GF & 193.0 & A & 437.0 & $A$ & 60.3 & $A$ & 18.6 & $A$ & 4.2 & A & 24.7 & A & 230 & $A$ \\
\hline & LSD & 51.0 & & 237.5 & & 24.5 & & 4.5 & & 0.9 & & 15.0 & & 196 & \\
\hline \multirow{5}{*}{60} & $\mathrm{~F}$ & 264.0 & $\mathrm{a}$ & 555.4 & $b$ & 81.8 & $\mathrm{~b}$ & 19.9 & $b$ & 4.3 & $b$ & 26.8 & $\mathrm{~b}$ & 475 & $b$ \\
\hline & FSf & 260.0 & $a$ & 718.7 & $a b$ & 99.4 & $a b$ & 24.2 & $a b$ & 4.7 & $a b$ & 27.2 & b & 435 & $b$ \\
\hline & G & 263.0 & $\mathrm{a}$ & 675.5 & $a b$ & 100.4 & $a b$ & 25 & $\mathrm{a}$ & 5.2 & $\mathrm{a}$ & 39.1 & $\mathrm{a}$ & 618 & $a$ \\
\hline & GF & 246.0 & $\mathrm{a}$ & 735.3 & $\mathrm{a}$ & 103.9 & $\mathrm{a}$ & 21.8 & $a b$ & 4.9 & $a b$ & 39.2 & $\mathrm{a}$ & 517 & $a b$ \\
\hline & LSD & 42.4 & & 178.0 & & 21.1 & & 4.8 & & 0.9 & & 10.5 & & 138 & \\
\hline \multirow{5}{*}{90} & $\mathrm{~F}$ & 270.0 & Z & 571.0 & Z & 78.3 & $\mathrm{Z}$ & 24.2 & $Z$ & 7.4 & $\mathrm{Z}$ & 21.2 & Z & 442 & $Z$ \\
\hline & FSf & 288.0 & Z & 721.0 & $Y$ & 114.3 & $Y$ & 27.9 & YZ & 9.4 & $Y$ & 22.5 & z & 456 & $Y Z$ \\
\hline & G & 294.0 & Z & 751.0 & $Y$ & 119.4 & $Y$ & 31.2 & $Y$ & 10.6 & $Y$ & 29.0 & $Y$ & 536 & $Y$ \\
\hline & GF & 277.0 & Z & 679.0 & $Y$ & 107.7 & $Y$ & 29.1 & $Y Z$ & 9.5 & $Y$ & 27.7 & $Y$ & 484 & $Y Z$ \\
\hline & LSD & 45.6 & & 100.8 & & 25.2 & & 6.9 & & 1.8 & & 5 & & 90.2 & \\
\hline
\end{tabular}

DAT, days after transplanting; Chemical fertilizer (F), bacterial grass culture (G), $1 / 3$ volume of $G$ plus $2 / 3 \mathrm{~F}$ (GF), and F plus synthetic fungicide (active ingredients 45\% carbendazim 45\% and 95 metalaxyl-M, Lidochamgold, Seongbo Chemical) (FSf). The experiments to investigate the effect of a bacterial grass culture on tomato growth and fungal disease control were carried out in the greenhouses of Chonnam National University in Gwangju, Korea. Soil type at this site is a loam (http://soil.rda.go.kr/geoweb). The tomato cultivar used was Younghwa (Daenong Company). Tomato seeds were sown in bed soil (Bio bed soil I, Heong Nong Seed, Korea) in $54 \times 45 \mathrm{~mm}^{2}$ plastic cell plug trays, and then grown at $24^{\circ} \mathrm{C}$ and $60 \%$ relative humidity in an artificially illuminated room (12,000 lux) with a 16-h photoperiod. Twelve four-week-old seedlings were transplanted in a plot with a raised bed with a row spacing of $0.6 \mathrm{~m}$ and a plant spacing of $0.4 \mathrm{~m}$ within rows on August 21 of 2013. The experimental area of one plot was a $2.5 \times 1.0 \mathrm{~m}^{2}$. The experiment was arranged in a randomized complete block design (RCBD) with four treatments and three replications. Treatments were G, F, GF and FSf. To prepare G for use in this experiment, a grass culture medium (g/l; fresh Kentucky blue grass powder 178; urea 2.8; single superphosphate 8.8; potassium chloride 1.6; magnesium sulfate 1.0; calcium chloride 1.0; yeast 0.1; sodium molybdate 0.05 ; zinc sulfate 0.06 ; crab shell powder (Purne Co., Korea) 0.8; gelatin powder (Geltech Co., Korea) 0.2 ) was autoclaved, inoculated with P. ehimensis $\mathrm{KWN} 38$ and incubated for 5 days at $30^{\circ} \mathrm{C}$. The $\mathrm{F}$ treatment $\left(10.2: 5.15: 6.1 \mathrm{~kg} ; \mathrm{N}\right.$ : $\mathrm{P}_{2} \mathrm{O}_{5}$ : $\mathrm{K}_{2} \mathrm{O}$ per $1,000 \mathrm{~m}^{2}$ ) was applied directly to soil using urea for $\mathrm{N}$, mono superphosphate for $\mathrm{P}_{2} \mathrm{O}_{5}$, and potassium chloride for $\mathrm{K}_{2} \mathrm{O}$ by the chemical fertilizer recommendation for greenhouse tomatoes in Korea on July 21, September 21, and October 21 of 2013 . A half amount of the total chemical fertilizer for each F, FSf, and GF treatment was applied to the soil by side-dressing as a basal application before transplanting the seedlings, while the remaining half was divided into two more side dressings applied one and two months after transplanting the seedlings. Chemical fertilizer was dissolved with distilled water and used. The GF treatment received 1/3 volume of $G$ with $2 / 3$ amount of $F$. Ninety-seven $\mathrm{ml}$ and $32 \mathrm{ml}$ of $\mathrm{G}$ were treated weekly to the root zone of each tomato plant in the $\mathrm{G}$ and GF, respectively, treatments for 16 weeks. After the FSf treatment was prepared by dissolving $1.0 \mathrm{~g}$ fungicide into $1 \mathrm{I}$ of distilled water, it was applied at the same time in each plot. Three additional sprays in all treatments were applied to the foliar portion of the plants every 20 days between 60 days after transplanting and 90 DAT after the first symptoms of early blight and gray mold disease occurred on the leaves and stems. For foliar application, a half amount of the total chemical fertilizer for $F$ was applied after dissolving with distilled water. Ninety-seven $\mathrm{ml}$ and $32 \mathrm{ml}$ of $\mathrm{G}$ were applied to the leaf surface of one tomato plant in the G and GF, respectively. The results did not indicate a cumulative value, but average per plant. LSD, Least significant difference. Means with a common letter in the same column and sampling time are not significantly different each other at the 0.05 level. 
significant difference tests $(P<0.05)$ using statistical analytical software (SAS, version 9.2, SAS Institute Inc., Cary, NC, USA). Correlation analyses were performed between leaf infection, fruit weight, and shoot fresh weight of tomato planted at 90 DAT in the $G$ treatment. The treatments were arranged in a randomized complete block design, with twelve seedlings in a plot with three replicates of each treatment. All assays were repeated once and also included three replicates per treatment.

\section{Results}

Growth and yield parameters of tomato plants. Shoot weights, root weights, fruit number, and fruit weights of tomato plants were not significantly different among treatments at 30 DAT. Plant height was not significantly different at all observation times. However, at 60 DAT shoot fresh and dry weights in GF were greater than those of F. Moreover, root fresh and dry weights and fruit number and weights in $G$ were significantly different compared to the control $F$ (Table 1). At 90 DAT, treatments G, GF, and FSf had greater shoot fresh weights and root dry weights than those of $F$. The num-

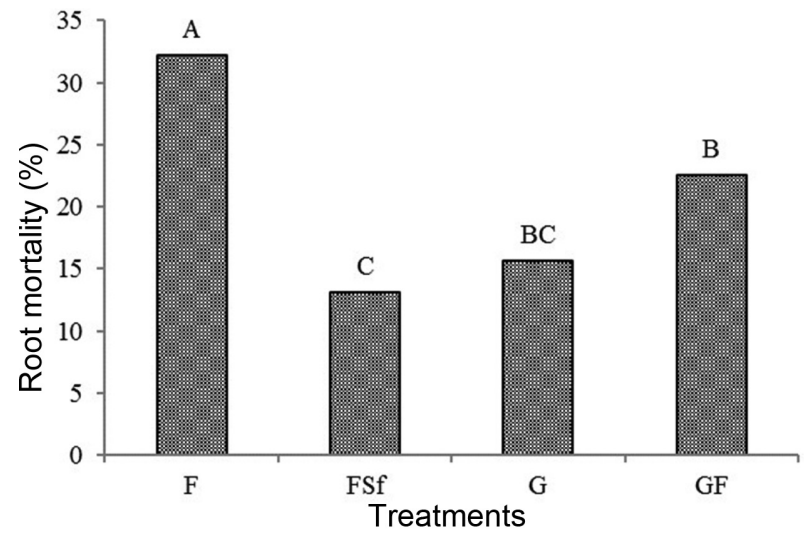

Fig. 1. Root mortality of tomato plants treated with chemical fertilizer (F), F and synthetic fungicide (FSf), grass culture (G), and $1 / 3$ volume of $\mathrm{G}$ plus 2/3 $\mathrm{F}$ (GF) treatment at 90 days after transplanting. For the assay of root mortality, dried fresh roots $(500 \mathrm{mg})$ were added to $25 \mathrm{ml}$ of conical tube (SPL life science, Korea) containing $10 \mathrm{ml}$ of $0.6 \%$ 2,3,5-triphenyltetrazolium chloride in $0.05 \mathrm{M}$ phosphate buffer ( $\mathrm{pH} 7.4$ ) and incubated for $24 \mathrm{~h}$ in the dark at $30^{\circ} \mathrm{C}$ After incubation, roots were rinsed twice with deionized water. Formazan present in the root was extracted twice with 95\% ethanol at $70^{\circ} \mathrm{C}$ for $4 \mathrm{~h}$. Combined extracts were adjusted to a final volume of $20 \mathrm{ml}$ with $95 \%$ ethanol. Absorbance was read at $490 \mathrm{~nm}$ with a UV-spectrophotometer (UV-1650PC, Shimadzu, Japan). A standard curve was made using different proportions of living roots and killed roots to calculate root mortality. ber of fruits in $\mathrm{G}$ and GF was significantly different compared to $F$ and $F S f$. Fruit weight in $G$ was higher than that in $F$, while fruit weight in GF and FSf were not different compared to that in other treatments.

Root mortality. Tomato roots of treatments had different mortality percentages. Treatment $\mathrm{F}$ showed the highest mortality value (32.2\%), which was significantly different compared with the other treatments (Fig. 1). Application of $G$ reduced root mortality by $48.4 \%$ in comparison with $\mathrm{F}$.

Fungal disease incidence on leaves and stems of tomato plants. Leaves and stems of tomato plants in all treatments did not show symptoms of foliar or stem diseases at the early growth stage until 30 DAT. However, the symptoms of early blight disease caused by $A$. solani and gray mold diseases caused by $B$. cinerea were observed on the lower leaves and stems of tomato plants in all treatments at 60 and 90 DAT (Fig. 2A, C, E, F). The level of early blight disease in F was more severe that of G (Fig. 2A, B). This disease was confirmed by the morphology of symptoms observed on both upper and lower leaf surfaces (Fig. 2C, D). The level of fungal disease incidence was significantly highest in $\mathrm{F}$ at both observation times (Table 2). At 60 and 90 DAT, treatment $\mathrm{G}$ reduced early blight disease by 43 and $64 \%$, respectively, and gray mold diseases by 55 and 44\%, compared to F. At 60 DAT, G, GF, and FSf had the same protection level against early blight and gray mold diseases.

\section{Correlations between disease incidence and growth}

parameters. At $90 \mathrm{DAT}$ in the $\mathrm{G}$ treatment, the correlation coefficients between diseases and growth parameters are shown in Table 3. Diseased leaves and shoot fresh weights were strongly and significantly correlated $(r=1.000, P<0.01)$. Diseased stem and shoot length were negatively correlated $(r=-0.999, P<0.05)$. No significant correlations were observed between diseased leaves and stems, and fruit number and weight. As the disease occurred on leaves, the shoot fresh weight increased. Shoot length decreased with the increase in disease incidence on the stems. Fruit number and weight were not affected by the incidence of disease on leaves and stems.

Bacterial and fungal populations in the soil. A significant population of $P$. ehimensis KWN38 was observed on 

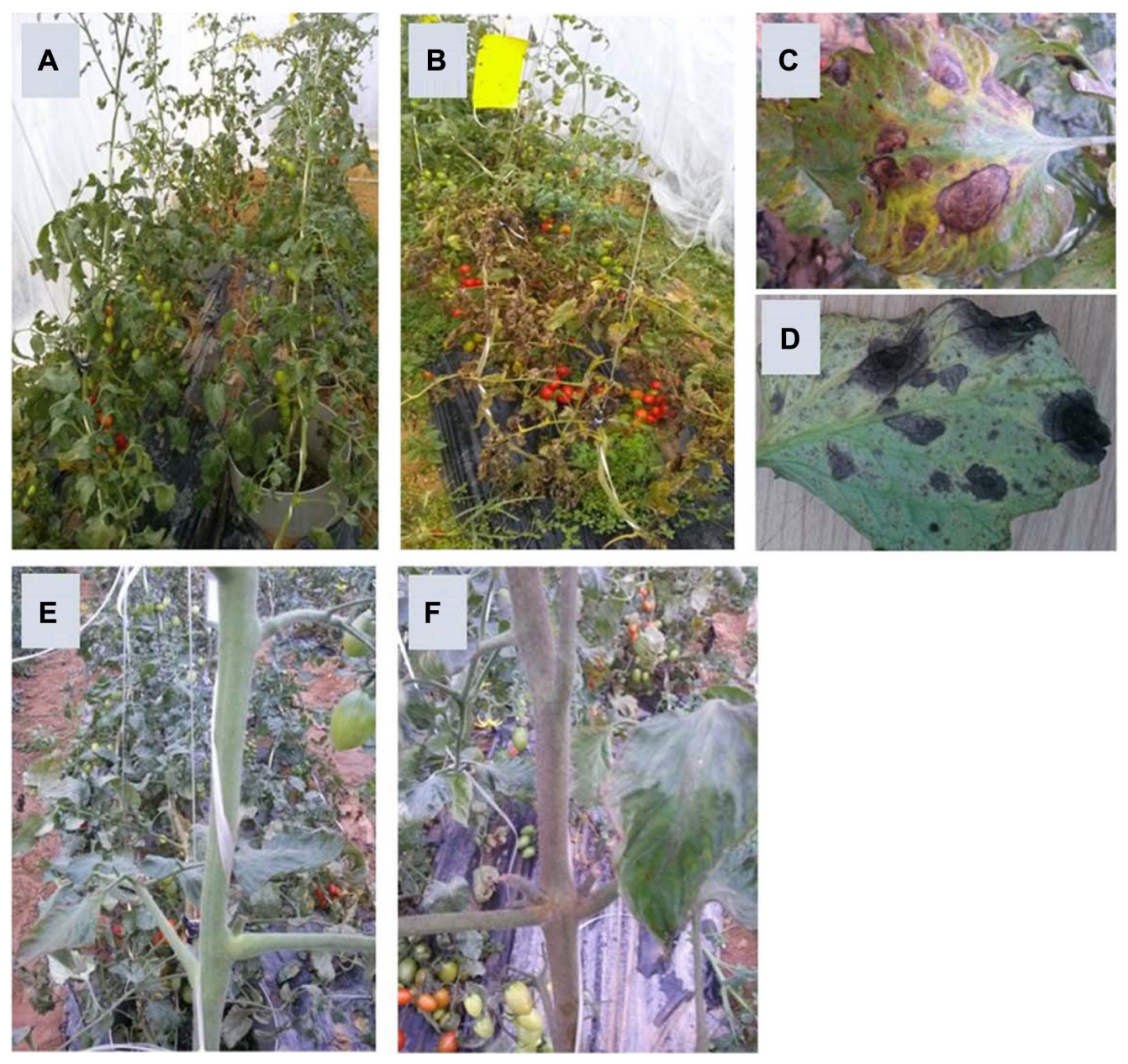

Fig. 2. Tomato plants with healthy leaves in treatment $G(A)$, plants with leaves of early blight in $F(B)$, symptom of early blight disease on upper leaf surface (C), symptom of early blight disease on lower leaf surface (D), healthy stem of tomato plant in $G(E)$, and gray mold disease symptom on the stem of tomato plant in F (F). G: bacterial grass culture, F: chemical fertilizer.

TSA for G and GF (Fig. 3A). Total bacterial CFUs in G and GF were significantly higher than those in $\mathrm{F}$ and FSF at 60 and 90 DAT (Fig. 4A). Fungicide treatment had the lowest CFUs at all observation times. Seven different fungal species were observed in the soil from treatment $F$ (Fig. 3B). The highest fungal colony numbers were found in treatment $F$ at 30 and 90 DAT (Fig. 4B). $G$ and GF had lower numbers of fungal colonies than in $\mathrm{F}$ at 60 and 90 DAT. G reduced fungal colony numbers in soil by 35 and $45 \%$, compared to the populations in $\mathrm{F}$ at 60 and 90 DAT.

Enzyme activity in soil. DHA in F, G, and GF was higher than the activity in FSf at 30 and 60 DAT. At 90 DAT, G and GF had higher enzyme activities than in FSf but were not different from that in F (Fig. 5). Soil cellulase activity in the root zones of tomato plants was not significantly different across treatments at 30 DAT. Enzyme activity in GF was significantly higher than in the other treatments at 60 DAT. On the final sampling day (90 DAT), treatments $G$ and GF showed higher cellulase activity than F and FSf (Fig. 6).

\section{Discussion}

Increased plant growth and yield of tomato induced by different genera of plant growth-promoting rhizobacteria, such as Pseudomonas, Bacillus, and Paenibacillus, have been reported (Almaghrabi et al., 2013; Khan et al., 2012). In the present study, the increased root fresh and dry weights of tomato plants treated with P. ehimensis KWN38 (in G and GF) compared to the weights of non-treated plants in $\mathrm{F}$ and FSf at 60 DAT suggests that $P$. ehimensis KWN38 is also a growth-promoting bacterium. Larger root systems might 
Table 2. The disease incidence level of early blight on leaves and gray mold on stems of tomato after different treatments

\begin{tabular}{cccccc}
\hline DAT & Treatment & \multicolumn{2}{c}{ Diseased leaf (\%) } & \multicolumn{2}{c}{ Diseased stem (\%) } \\
\hline \multirow{4}{*}{60} & F & 18.3 & A & 20.5 & A \\
& FSf & 5.5 & B & 7.8 & B \\
& G & 7.8 & B & 11.2 & B \\
& GF & 9.5 & B & 12.6 & B \\
& LSD & 5 & & 7.1 & \\
\hline \multirow{6}{*}{90} & F & 35.5 & A & 39.4 & A \\
& FSf & 18.3 & C & 15.2 & C \\
& G & 22.6 & BC & 17.3 & BC \\
& GF & 24.3 & B & 25.5 & B \\
& LSD & 4.9 & & 8.9 & \\
\hline
\end{tabular}

DAT, days after transplanting; Chemical fertilizer $(\mathrm{F})$, bacterial grass culture (G), $1 / 3$ volume of $G$ plus $2 / 3 \mathrm{~F}$ (GF), and $F$ plus synthetic fungicide (active ingredients $45 \%$ carbendazim $45 \%$ and 95 metalaxyl-M, Lidochamgold, Seongbo Chemical) (FSf). The experiments to investigate the effect of a bacterial grass culture on tomato growth and fungal disease control were carried out in the greenhouses of Chonnam National University in Gwangju, Korea. Soil type at this site is a loam (http://soil.rda. go.kr/geoweb). The tomato cultivar used was Younghwa (Daenong Company). Tomato seeds were sown in bed soil (Bio bed soil I, Heong Nong Seed, Korea) in $54 \times 45 \mathrm{~mm}^{2}$ plastic cell plug trays, and then grown at $24^{\circ} \mathrm{C}$ and $60 \%$ relative humidity in an artificially illuminated room $(12,000$ lux $)$ with a 16 -h photoperiod. Twelve four-week-old seedlings were transplanted in a plot with a raised bed with a row spacing of $0.6 \mathrm{~m}$ and a plant spacing of $0.4 \mathrm{~m}$ within rows on August 21 of 2013. The experimental area of one plot was a $2.5 \times 1.0 \mathrm{~m}^{2}$. The experiment was arranged in a randomized complete block design (RCBD) with four treatments and three replications. Treatments were G, F, GF and FSf. To prepare $\mathrm{G}$ for use in this experiment, a grass culture medium ( $\mathrm{g} / \mathrm{l}$; fresh Kentucky blue grass powder 178; urea 2.8; single superphosphate 8.8; potassium chloride 1.6; magnesium sulfate 1.0; calcium chloride 1.0; yeast 0.1 ; sodium molybdate 0.05 ; zinc sulfate 0.06 ; crab shell powder (Purne Co., Korea) 0.8; gelatin powder (Geltech Co., Korea) 0.2) was autoclaved, inoculated with $P$. ehimensis KWN38 and incubated for 5 days at $30^{\circ} \mathrm{C}$. The F treatment (10.2: 5.15: $6.1 \mathrm{~kg} ; \mathrm{N}: \mathrm{P}_{2} \mathrm{O}_{5}: \mathrm{K}_{2} \mathrm{O}$ per $1,000 \mathrm{~m}^{2}$ ) was applied directly to soil using urea for $\mathrm{N}$, mono superphosphate for $\mathrm{P}_{2} \mathrm{O}_{5}$, and potassium chloride for $\mathrm{K}_{2} \mathrm{O}$ by the chemical fertilizer recommendation for greenhouse tomatoes in Korea on July 21, September 21, and October 21 of 2013. A half amount of the total chemical fertilizer for each F, FSf, and GF treatment was applied to the soil by side-dressing as a basal application before transplanting the seedlings, while the remaining half was divided into two more side dressings applied one and two months after transplanting the seedlings. Chemical fertilizer was dissolved with distilled water and used. The GF treatment received $1 / 3$ volume of $\mathrm{G}$ with $2 / 3$ amount of $F$. Ninety-seven $\mathrm{ml}$ and $32 \mathrm{ml}$ of $\mathrm{G}$ were treated weekly to the root zone of each tomato plant in the $G$ and GF, respectively, treatments for 16 weeks. After the FSf treatment was prepared by dissolving $1.0 \mathrm{~g}$ fungicide into $1 \mathrm{I}$ of distilled water, it was applied at the same time in each plot. Three additional sprays in all treatments were applied to the foliar portion of the plants every 20 days between 60 days after transplanting and 90 DAT after the first symptoms of early blight and gray mold disease occurred on the leaves and stems. For foliar application, a half amount of the total chemical fertilizer for $F$ was applied after dissolving with distilled water. Ninety-seven $\mathrm{ml}$ and 32 $\mathrm{ml}$ of $\mathrm{G}$ were applied to the leaf surface of one tomato plant in the $\mathrm{G}$ and GF, respectively. The level of fungal disease incidence is calculated as the ratio of diseased leaf number per total leaf number. LSD, Least significant difference. Means with a common letter in the same column and sampling time are not significantly different each other at the 0.05 level. be the main reason for the increased shoot weights and fruit weights at 90 DAT. One of the mechanisms of growth promotion in this experiment may be related to the production of indole-3-acetic acid by P. ehimensis KWN38 (Naing et al., 2014b).

The accumulation of antagonistic bacteria in soil influences the health of plants. In disease-suppressive soils, fungal pathogens are highly suppressed by the accumulation of antagonistic strains, mainly through direct control mechanism such as antibiosis (Mazzola, 2002). Significant populations of $P$. ehimensis KWN38 were recovered on PDA from the $G$ and GF treatments, confirming accumulation of the antagonistic strain. Lesser numbers of soil fungal colonies in $\mathrm{G}$ and GF compared to those in $\mathrm{F}$ may be regarded as the suppression of fungal growth and spore production in soil by secondary metabolites produced by $P$. ehimensis KWN38. Some genera of important plant pathogens, like Fusarium, Rhizoctonia, Phytophthora, and Alternaia, were recovered from the soil in $\mathrm{F}$ and their morphologies were clearly distinctive from other unknown fungi. In addition, the accumulation of fungal populations in F caused increased root mortality compared to the other treatments, which might have resulted in the lower shoot and root growth in F at 90 DAT. Lower root efficiency for plant nutrient uptake could be the principal factor that decreased fruit set, fruit retention, and fruit weight per plant in $\mathrm{F}$ (Table 1).

DHA in soil is one of the most important enzymes to predict the overall microbial activity of soil (Gu et al., 2009; Lee et al., 2000). Measurement of DHA is considered a good and adequate measure of microbial oxidative activities in soil. In this experiment, DHA was proportional to the population of microorganisms in soil because more bacterial populations were observed in G, GF, and F (Fig. 4A, 5). Although the fungal populations in $\mathrm{G}$ and $\mathrm{GF}$ at 90 DAT were lower than that in $\mathrm{F}$, the DHAs of these treatments were not significantly different. This result shows that bacterial DHA mainly contributed to the increased soil DHA, rather than enzymes produced by fungi. Consistently lower DHA in FSf was considered to be due to the suppression of the soil microbial community by the applied synthetic fungicide, as different fungicides significantly decreased soil DHA in a previous report (Chen et al., 2001).

Cell wall-degrading enzymes, such as chitinase, $\beta-1,3-$ glucanase, and cellulase, play a major role in plant fungal disease protection (Ordentlich et al. 1988; Richter et al., 2011; 
Table 3. Correlation analyses were performed between disease incidence and growth parameter of tomato plants at $90 \mathrm{DAT}$ in $\mathrm{G}$ treatment

\begin{tabular}{|c|c|c|c|c|c|c|c|c|c|}
\hline & $\begin{array}{c}\text { Diseased } \\
\text { leaf }\end{array}$ & $\begin{array}{c}\text { Diseased } \\
\text { stem }\end{array}$ & $\begin{array}{l}\text { Shoot } \\
\text { length }\end{array}$ & $\begin{array}{c}\text { Shoot fresh } \\
\text { weight }\end{array}$ & $\begin{array}{c}\text { Shoot dry } \\
\text { weight }\end{array}$ & $\begin{array}{c}\text { Root fresh } \\
\text { weight }\end{array}$ & $\begin{array}{c}\text { Root dry } \\
\text { weight }\end{array}$ & $\begin{array}{c}\text { Fruit } \\
\text { number }\end{array}$ & $\begin{array}{c}\text { Fruit } \\
\text { weight }\end{array}$ \\
\hline Diseased leaf & 1.000 & & & & & & & & \\
\hline Diseased stem & -0.700 & 1.000 & & & & & & & \\
\hline Shoot length & 0.723 & $-0.999^{*}$ & 1.000 & & & & & & \\
\hline Shoot fresh weight & $1.000^{* *}$ & -0.700 & 0.723 & 1.000 & & & & & \\
\hline Shoot dry weight & 0.966 & -0.491 & 0.519 & 0.966 & 1.000 & & & & \\
\hline Root fresh weight & 0.933 & -0.397 & 0.427 & 0.933 & 0.994 & 1.000 & & & \\
\hline Root dry weight & 0.913 & -0.349 & 0.379 & 0.913 & 0.988 & $0.999^{*}$ & 1.000 & & \\
\hline Fruit number & 0.979 & -0.541 & 0.569 & 0.979 & $0.998^{*}$ & 0.987 & 0.977 & 1.000 & \\
\hline Fruit weight & 0.984 & -0.564 & 0.590 & 0.984 & 0.996 & 0.982 & 0.971 & $0.999^{*}$ & 1.000 \\
\hline
\end{tabular}

*,** Significant at the 0.05 and 0.01 probability levels, respectively. Each value is the Pearson's correlation coefficient (r).
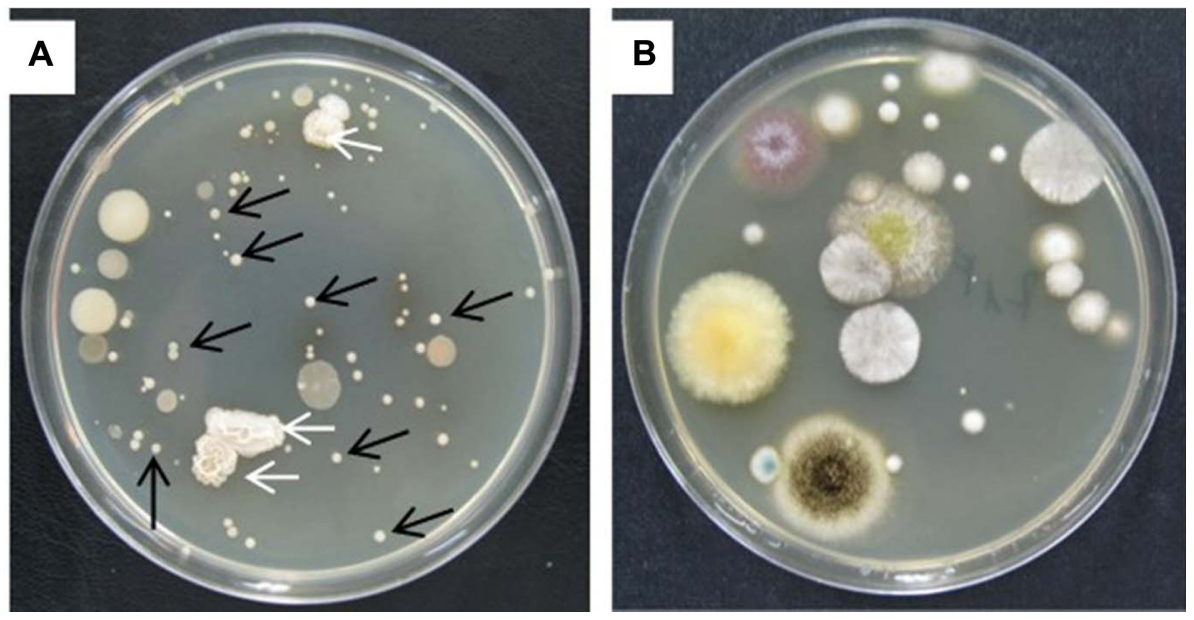

Fig. 3. Colonies of bacteria from soil of $\mathrm{G}$ on tryptone soy agar medium (A). Arrows show a significant population of Paenibacillus ehimensis KWN38 indicated in early morphology with a bright milky color (black arrows) and the shrunken surface of colonies at later days (white arrows). The colony shape and color were compared with that of directly cultivated $P$. ehimensis KWN38 on TSA. $P$. ehimensis KWN38 was regarded as having the same shape and color. Colonies of fungi on potato dextrose agar medium inoculated from the soil of $\mathrm{F}$ (B). $\mathrm{G}$ : bacterial grass culture, F: chemical fertilizer.

Shetty et al., 2009). The microbial cellulolytic activity in soil indicates soil health and quality because it efficiently degrades soil organic matter to supply other microorganisms (Toresani et al., 1998; Zhao et al., 2005). The increased soil cellulase activity due to $P$. ehimensis KWN38 inoculation in this study agrees with Jung et al. (2004), who reported enhanced cellulase activity due to the inoculation of $P$. illinoisensis to the root zone of pepper. $P$. lentimorbus B-30488 ${ }^{r}$ inoculated tomato plants increased the production of defense-regulated genes and showed more resistance to early blight disease caused by A. solani (Khan et al., 2012). Thus, this mechanism of sys- temic induced resistance might explain the reduction of early late blight disease in $P$. ehimensis KWN38-treated plants compared to the non-treated control plants (Table 2).

Paenibacillus species have a growth inhibitory effect over a wide range of fungal genera, including Phytophthora, Fusarium, Alternaria, and Botrytis (Budi et al., 2000; Jung et al., 2004; Khan et al., 2012). Production of important antibiotics by different species of Paenibacillus was reported (Huang et al., 2013; Li and Jensen, 2008; Qian et al., 2012). In our previous report, the supernatant of a bacterial grass culture broth contained chitinase, $\beta-1,3$-glucanase, cellulase, protease, and 

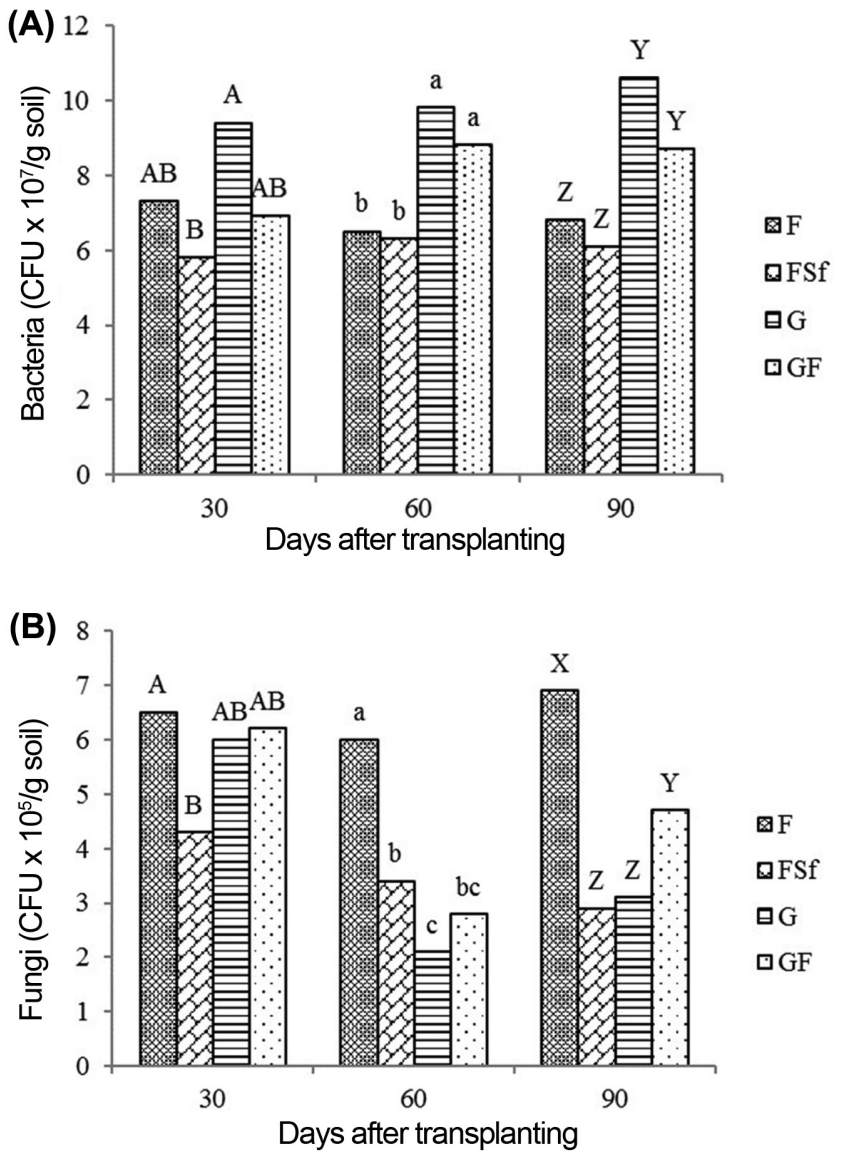

Fig. 4. Population of bacteria (A) and fungi (B) in the rhizosphere of tomato plants treated with chemical fertilizer $(F), F$ and synthetic fungicide (FSf), grass culture (G), and $1 / 3$ volume of $G$ plus 2/3 F (GF). LSD, least significant difference. Means are from six replicates. Mean with a common letter in the sampling time are not significantly different each other at the 0.05 level. A half amount of the total chemical fertilizer for each F, FSf, and GF treatment was applied to the soil by side-dressing as a basal application before transplanting the seedlings, while the remaining half was divided into two more side dressings applied one and two months after transplanting the seedlings. However, GF treatment was received with $2 / 3$ concentration of the fertilizer recommendation. Ninety-seven $\mathrm{ml}$ and $32 \mathrm{ml}$ of $\mathrm{G}$ were treated weekly to the root zone of each tomato plant in the $\mathrm{G}$ and $\mathrm{GF}$, respectively, treatments for 16 weeks. $F$ was treated after it was dissolved with distilled water. After the FSf treatment was prepared by dissolving $1.0 \mathrm{~g}$ fungicide into $1 \mathrm{I}$ of distilled water, it was applied at the same time in each plot. Three additional sprays in all treatments were applied to the foliar portion of the plants after transplanting and 90 DAT after the first symptoms of early blight and gray mold disease occurred on the leaves and stems.

butanol-soluble antifungal metabolites (Naing et al., 2014a). This could be the primary factor that reduced the incidence of early leaf blight and gray mold diseases on the aerial parts

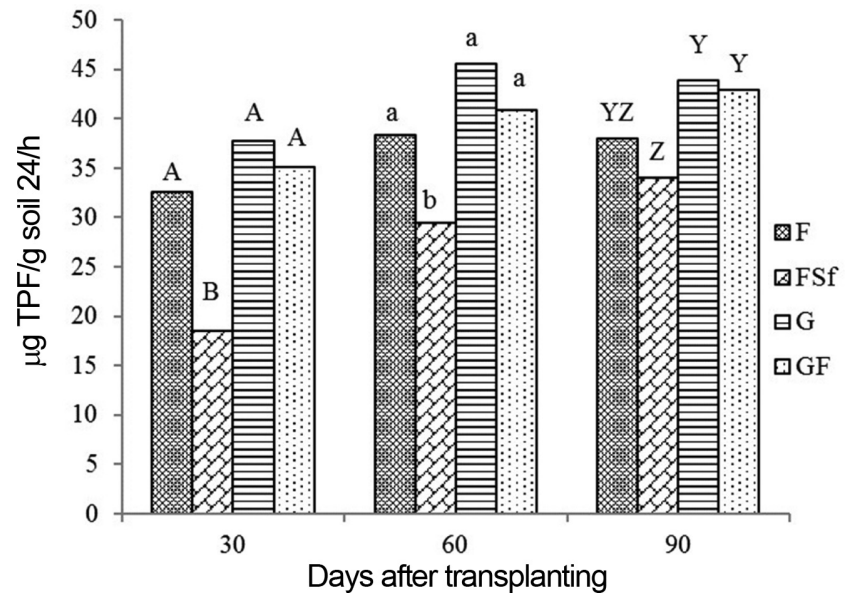

Fig. 5. Dehydrogenase activities in soil of tomato plants treated with chemical fertilizer (F), F and synthetic fungicide (FSf), grass culture $(G)$, and $1 / 3$ volume of $G$ plus $2 / 3 F(G F)$. LSD, least significant difference. Mean from six replicates. Mean with a common letter in the sampling time are not significantly different each other at 0.05 level. A half amount of the total chemical fertilizer for each F, FSf, and GF treatment was applied to the soil by side-dressing as a basal application before transplanting the seedlings, while the remaining half was divided into two more side dressings applied one and two months after transplanting the seedlings. However, GF treatment was received with $2 / 3$ concentration of the fertilizer recommendation. Ninety-seven $\mathrm{ml}$ and $32 \mathrm{ml}$ of $\mathrm{G}$ were treated weekly to the root zone of each tomato plant in the G and GF, respectively, treatments for 16 weeks. F was treated after it was dissolved with distilled water. After the FSf treatment was prepared by dissolving $1.0 \mathrm{~g}$ fungicide into $1 \mathrm{I}$ of distilled water, it was applied at the same time in each plot. Three additional sprays in all treatments were applied to the foliar portion of the plants after transplanting and 90 DAT after the first symptoms of early blight and gray mold disease occurred on the leaves and stems.

of tomato plants in G and GF. In the same context, the lower root mortality in $\mathrm{G}$ and $\mathrm{GF}$ than in $\mathrm{F}$ is considered to be related to the high population of $P$. ehimensis KWN38 in the rhizosphere, the secondary antimicrobial metabolites, and the exogenous cellulase produced in the grass culture broth. However, in this experiment, no significant correlations were statistically observed between disease incidence and tomato yield.

In conclusion, tomato plants treated with full-strength or diluted bacterial grass cultures suppressed the incidence of two important fungal diseases and reduced the mortality of roots compared to untreated control plants. Moreover, these plants had better vegetative growth and yield. All results, including suppression of the soil fungal population, suggest that the application of a grass culture with $P$. ehimensis 


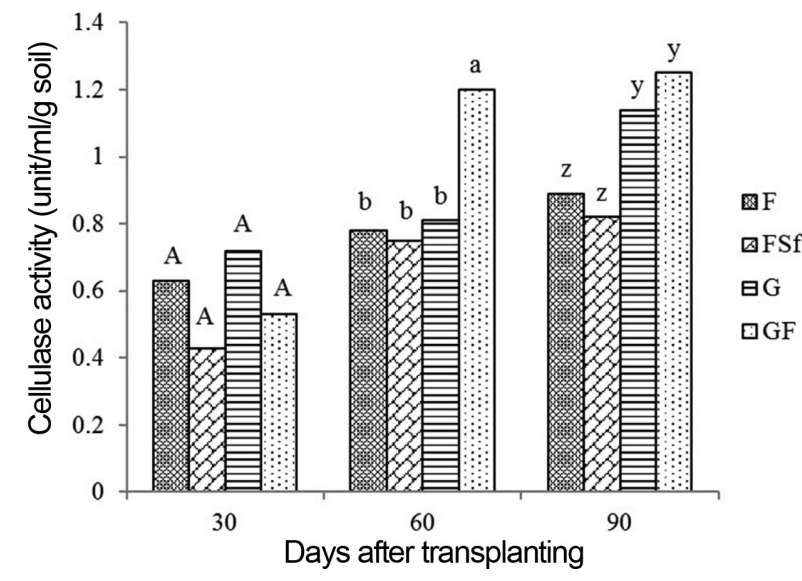

Fig. 6. Cellulase activities in soil treated with chemical fertilizer $(F)$, $F$ and synthetic fungicide (FSf), grass culture (G), and 1/3 G and 2/3 $F(G F)$. LSD, least significant difference. Means are from six replicates. Means with a common letter in the sampling time are not significantly different each other at 0.05 level. A half amount of the total chemical fertilizer for each F, FSf, and GF treatment was applied to the soil by side-dressing as a basal application before transplanting the seedlings, while the remaining half was divided into two more side dressings applied one and two months after transplanting the seedlings. However, GF treatment was received with $2 / 3$ concentration of the fertilizer recommendation. Ninety-seven $\mathrm{ml}$ and $32 \mathrm{ml}$ of $\mathrm{G}$ were treated weekly to the root zone of each tomato plant in the $G$ and GF, respectively, treatments for 16 weeks. $F$ was treated after it was dissolved with distilled water. After the FSf treatment was prepared by dissolving $1.0 \mathrm{~g}$ fungicide into $1 \mathrm{I}$ of distilled water, it was applied at the same time in each plot. Three additional sprays in all treatments were applied to the foliar portion of the plants after transplanting and 90 DAT after the first symptoms of early blight and gray mold disease occurred on the leaves and stems.

KWN38 is a reliable alternative for synthetic fungicides to control aerial and root fungal pathogens in tomato.

\section{Conflicts of Interest}

The authors declare that they have no competing and commercial interests in this work.

\section{Acknowledgement}

This work was supported by Korea Institute of Planning and Evaluation for Technology in Food, Agriculture, Forestry and Fisheries (IPET) through Agri-Bio industry Technology Development Program (or Project), funded by Ministry of Agriculture, Food and Rural Affairs (MAFRA)(314084-03).

\section{References}

Ahemad, M. and Khan, M. S. 2012. Alleviation of fungicide-induced phytotoxicity in greengram [Vigna radiata (L.) Wilczek] using fungicide-tolerant and plant growth promoting Pseudomonas strain. Saudi J. Biol. Sci. 19: 451-459.

Algam, S. A. E., Mahdi, A. A., Li, B. and Xie, G. L. 2013. Effects of chemical inducers and Paenibacillus on tomato growth promotion and control of bacterial wilt. Asian J. Plant Pathol. 7: 15-28.

Almaghrabi, O. A., Massoud, S. I. and Abdelmoneim, T. S. 2013. Influence of inoculation with plant growth promoting rhizobacteria (PGPR) on tomato plant growth and nematode reproduction under greenhouse conditions. Saudi J. Biol. Sci. 20: 57-61.

Ash, C., Priest, F. G. and Collins, M. D. 1993. Molecular identification of rRNA group 3 bacilli (Ash, Farrow, Wallbanks and Collins) using a PCR probe test. Proposal for the creation of a new genus Paenibacillus. Antonie Van Leeuwenhoek 64: 253-260.

Bergougnoux, V. 2014. The history of tomato: From domestication to biopharming. Biotechnol. Adv. 32: 170-189.

Bloemberg, G. V. and Lugtenberg, B. J. 2001. Molecular basis of plant growth promotion and biocontrol by rhizobacteria. Curr. Opin. Plant Biol. 4: 343-350.

Budi, S. W., van Tuinen, D., Arnould, C., Dumas-Gaudot, E., Gianinazzi-Pearson, V. and Gianinazzi, S. 2000. Hydrolytic enzyme activity of Paenibacillus sp. strain B2 and effects of the antagonistic bacterium on cell integrity of two soil-borne pathogenic fungi. Appl. Soil Ecol. 15: 191-199.

Chaudhry, V., Chauhan, P. S., Mishra, A., Goel, R., Asif, H. H., Mantri, S. S., Bag, S. K., Singh, S. K., Sawant, S. V. and Nautiyal, C. S. 2013. Insights from the draft genome of Paenibacillus lentimorbus NRRL B-30488, a promising plant growth promoting bacterium. J. Biotechnol. 168: 737-738.

Chen, S. K., Edwards, C. A. and Subler, S. 2001. A microcosm approach for evaluating the effects of the fungicides benomyl and captan on soil ecological processes and plant growth. Appl. Soil Ecol. 18: 69-82.

de la Noval, B., Perez, E., Martinez, B., Leon, O., Martinez-Gallardo, N. and Delano-Frier, J. 2007. Exogenous systemin has a contrasting effect on disease resistance in mycorrhizal tomato (Solanum lycopersicum) plants infected with necrotrophic or hemibiotrophic pathogens. Mycorrhiza 17: 449-460.

Deng, S. P. and Tabatabai, M. A. 1994. Cellulase activity of soils. Soil Biol. Biochem. 26: 1347-1354.

Filho, R. L., Romeiro, R. S. and Alves, E. 2010. Bacterial spot and early blight biocontrol by epiphytic bacteria in tomato plants. Pesq. Agropec. Bras. Brasília 45: 1381-1387.

Foolad, M. R., Merk, H. L. and Ashrafi, H. 2008. Genetics, genomics and breeding of late blight and early blight resistance in tomato. Crit. Rev. Plant Sci. 27: 75-107.

Gu, Y., Wang, P. and Kong, C. H. 2009. Urease, invertase, dehydrogenase and polyphenoloxidase activities in paddy soil influenced by allelopathic rice variety. Eur. J. Soil Biol. 45: 436-441. 
Huang, Z., Hu, Y., Shou, L. and Song, M. 2013. Isolation and partial characterization of cyclic lipopeptide antibiotics produced by Paenibacillus ehimensis B7. BMC Microbiol. 13: 87.

Jones, J. B., Jones, J. P., Stall, R. E. and Zitter, T. A. 1991. Infectious Diseases: Diseases Caused by Fungi. Compendium of Tomato Diseases. pp. 9-25. The American Phytopathological Society, St. Paul, MN, USA.

Jung, W. J., Jin, Y. L., Kim, Y. C., Kim, K. Y., Park, R. D. and Kim, T. H. 2004. Inoculation of Paenibacillus illinoisensis alleviates root mortality, activates of lignification-related enzymes, and induction of the isozymes in pepper plants infected by Phytophthora capsici. Biol. Control 30: 645-652.

Kang, B. R., Ko, S. J., Kim, D. I., Choi, D. S. and Kim, S. G. 2011. Determination of proper application timing and frequency for management of tomato leaf mold disease by commercially available microbial preparations. Res. Plant Dis. 17: 142-147.

Khan, N., Mishra, A. and Shekhar, C. 2012. Paenibacillus lentimorbus B-30488 ${ }^{r}$ controls early blight disease in tomato by inducing host resistance associated gene expression and inhibiting Alternaria solani. Biol. Control 62: 65-74.

Knievel, D. P. 1973. Procedures for estimating ratio of live or dead root dry matter in root core samples. Crop Sci. 13: 124-126.

Lal, S. and Tabacchioni, S. 2009. Ecology and biotechnological potential of Paenibacillus polymyxa: a minireview. Indian J. Microbiol. 49: 2-10.

Lee, S. M., Jung, J. Y. and Chung, Y. C. 2000. Measurement of ammonia inhibition of microbial activity in biological wastewater treatment process using dehydrogenase assay. Biotechnol. Lett. 22: 991-994.

$\mathrm{Li}$, J. and Jensen, S. 2008. Nonribosomal biosynthesis of fusaricidins by Paenibacillus polymyxa PKB1 involves direct activation of a $\mathrm{d}$ amino acid. Chem. Biol. 15: 118-127.

Mazzola, M. 2002. Mechanisms of natural soil suppressiveness to soilborne diseases. Antonie Van Leeuwenhoek 81: 557-564.

Myresiotis, C. K., Vryzas, Z. and Papadopoulou-Mourkidou, E. 2014. Enhanced root uptake of acibenzolar-S-methyl (ASM) by tomato plants inoculated with selected Bacillus plant growthpromoting rhizobacteria (PGPR). Appl. Soil Ecol. 77: 26-33.

Naing, K. W., Anees, M., Kim, S. J., Nam, Y., Kim, Y. C. and Kim, K. Y. 2014a. Characterization of antifungal activity of Paenibacillus ehimensis KWN38 against soilborne phytopathogenic fungi belonging to various taxonomic groups. Ann. Microbiol. 64: 55-63.

Naing, K. W., Anees, M., Nguyen, X. H., Lee, Y. S., Jeon, S. W., Kim, S. J., Kim, M. H. and Kim, K.Y. 2014b. Biocontrol of late blight disease (Phytophthora capsici) of pepper and the plant growth promotion by Paenibacillus ehimensis KWN38. J. Phytopathol. 162: 367-376.

Nielsen, P. and Sorensen, J. 1997. Multi-target and mediumindependent fungal antagonism by hydrolytic enzymes in Paenibacillus polymyxa and Bacillus pumilus strains from barley rhizosphere. FEMS Microbiol. Ecol. 22: 183-192.

Ordentlich, A., Elad, Y. and Chet, L. 1988. The role of chitinase of Serratia marcescens in biocontrol of Sclerotium rolfsii. Phythopathol- ogy 78: 84-88.

Qian, C. D., Wu, X. C., Teng, Y., Zhao, W. P., Li, O., Fang, S. G., Huang, Z. H. and Gao, H.C. 2012. Battacin (Octapeptin B5), a new cyclic lipopeptide antibiotic from Paenibacillus tianmuensis active against multidrug-resistant Gram-negative bacteria. Antimicrob. Agents Chemother. 56: 1458-1465.

Richter, B. S., Ivors, K., Shi, W. and Benson, D. M. 2011. Cellulase activity as a mechanism for suppression of Phytophthora root rot in mulches. Phytopathology 101: 223-230.

Riso, P., Visioli, F., Erba, D., Testolin, G. and Porrini, M. 2004. Lycopene and vitamin $C$ concentrations increase in plasma and lymphocytes after tomato intake. Effects on cellular antioxidant protection. Eur. J. Clin. Nutr. 58: 1350-1358.

Shaheen, M., Li, J., Ross, A. C., Vederas, J. C. and Jensen, S. E. 2011. Paenibacillus polymyxa PKB1 produces variants of polymyxin Btype antibiotics. Chem. Biol. 18: 1640-1648.

Shetty, N. P., Jensen, J. D., Knudsen, A., Finnie, C., Geshi, N., Blennow, A., Collinge, D. B. and Jørgensen, H. J. 2009. Effects of beta-1,3glucan from Septoria tritici on structural defence responses in wheat. J. Exp. Bot. 60:4287-300.

Son, S. H., Khan, Z., Kim, S. G. and Kim, Y. H. 2009. Plant growthpromoting rhizobacteria, Paenibacillus polymyxa and Paenibacillus lentimorbus suppress disease complex caused by rootknot nematode and fusarium wilt fungus. J. Appl. Microbiol. 107: 524-532.

Tabatabai, M. A. 1982. Soil enzymes. In: Methods of Soil Analysis. Part 2. Chemical and Microbiological Properties, eds. by A. L. Page, R. H. Miler and D. R. Keeney, pp. 903-947. American Society of Agronomy, Madison, WI, USA.

Toresani, S., Gomez, E., Bonel, B., Bisaro, V. and Montico, S. 1998. Cellulolytic population dynamics in a vertic soil under three tillage systems in the humid pampa of Argentina. Soil Till. Res. 49: 79-83.

Trabelsi, D. and Mhamdi, R. 2013. Microbial inoculants and their impact on soil microbial communities: a review. BioMed Res. Int. 2013: 863240.

von der Weid, l., Alviano, D. S., Santos, A. L., Soares, R. M., Alviano, C. S. and Seldin, L. 2003. Antimicrobial activity of Paenibacillus peoriae strain NRRL BD-62 against a broad spectrum of phytopathogenic bacteria and fungi. J. Appl. Microbiol. 95: 1143-1151.

Willcox, J. K., Catignani, G. L. and Lazarus, S. 2003. Tomatoes and cardiovascular health. Crit. Rev. Food Sci. Nutr. 43: 1-18.

Williamson, B., Tudzynski, B., Tudzynski, P. and van Kan, J. A. 2007. Botrytis cinerea: the cause of grey mould disease. Mol. Plant Pathol. 8: 561-580.

Zhao, L. J., Yang, X. N., Li, X. Y., Mu, W. and Liu, F. 2011. Antifungal, insecticidal and herbicidal properties of volatile components from Paenibacillus polymyxa Strain BMP-11. Agr. Sci. China 10: 728-736.

Zhao, Y., Li, W., Zhou, Z., Wang, L., Pan, Y. and Zhao, L. 2005. Dynamics of microbial community structure and cellulolytic activity in agricultural soil amended with two biofertilizers. Eur. J. Soil Biol. 41:21-29. 